\title{
Experimental Performance Evaluation of IPM Motor for Electric Vehicle System
}

\author{
Jin-Hong Kim ${ }^{1,2}$, Joon Sung Park ${ }^{1}$ and Chung-Yuen Won ${ }^{2}$ \\ ${ }^{1}$ Korea Electronics Technology Institute \\ ${ }^{2}$ University of Sungkyunkwan
}

\begin{abstract}
Electric vehicle (EV) appears to be one of the viable solutions for the growing concerns for environmental protection and the fast rate of depletion of world fuel oil supply. EV can become a viable alternative to the internal combustion engine only if they are able to meet certain reliability, safety, performance, and cost criteria. In addition, electrical vehicles have serious disadvantages because of the limitation on cruising range imposed by weight, capacity of the electric accumulators and long recharging time. Improvement of efficiency of motor traction drives is an important issue in pure electric vehicles to improve the running distance on one charge [1]. In this paper, the authors evaluate IPM motor by considering their influence on the performance of the vehicle. The evaluation is demonstrated experimentally.
\end{abstract}

Keywords: interior permanent magnet (IPM) motor, inverter, electric vehicle (EV)

\section{INTRODUCTION}

Worldwide demands for fuel-efficient, low-emission vehicles have motivated automotive industry to develop alternative powertrain architectures, such as Integrated Starter Alternator (ISA) systems for mild Hybrid Electric Vehicles (also known as stop/start vehicles), combination of an electric traction motor and a downsized Internal Combustion (IC) Engine for Hybrid Electric Vehicles (HEV), and ultimately pure Electric Vehicles (EV). A Hybrid Electric Vehicle utilizes a powertrain structure that combines an electric traction motor and an IC Engine (also known as thermal engine). Depending on performance requirements and vehicle packaging requirements, the electric traction motor and the IC engine maybe in series or in parallel. The traction motors used are typically AC electric machines, such as induction machines, reluctance machines, Brushless DC machines, or permanent magnet (PM) synchronous machines. Owe to their high efficiency, high torque density, fast dynamic response time, and wide operating speed range, interior permanent magnet (IPM) synchronous machines are often used as traction motors in today's electric vehicles [2].

Evaluation of traction motors for electric vehicles is a very important step. In motor drive for electrical vehicle, where real operation conditions are significantly different than rated conditions, the energy saving control is crucial for improvement of running distance on one charge [1].

In this work, we develop an inverter for evaluation of IPM motor for electric vehicle. And this paper will review our progress and current status of work on motors and inverters for EV system, and testing systems for evaluating the efficiency of the motor and inverter system.

\section{DEVELOPMENT OF THE INVERTER}

The Figure 1 illustrates an experimental test structure. The test structure is composed of four parts; the dynamo system part; the monitoring part; the load inverter system part; the inverter system part. Table II is the specification of the inverter system. Generally, when motor and inverter system for EV is tried to be of high output specifications, the higher voltage is, the less current, and consequently copper loss can be lowered and efficiency can be improved [3]. For this reason, we selected the driving voltage to 360 [V].

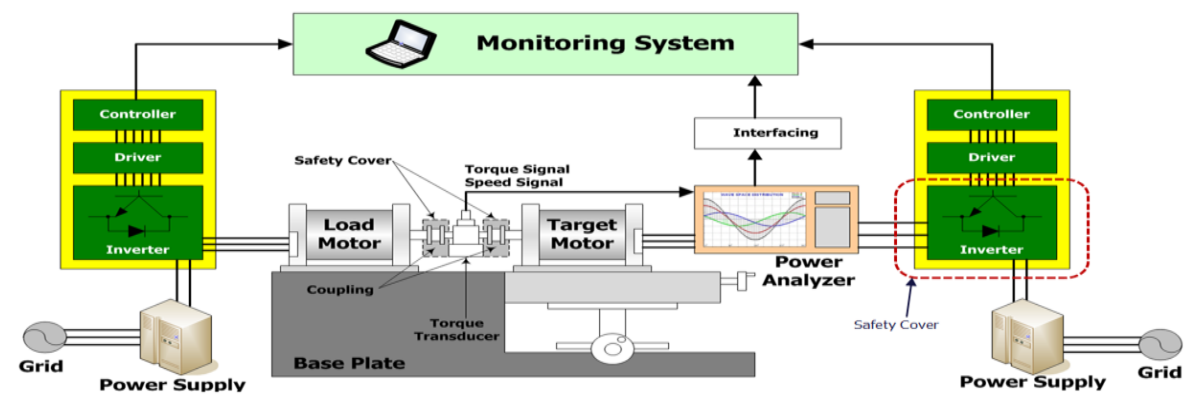




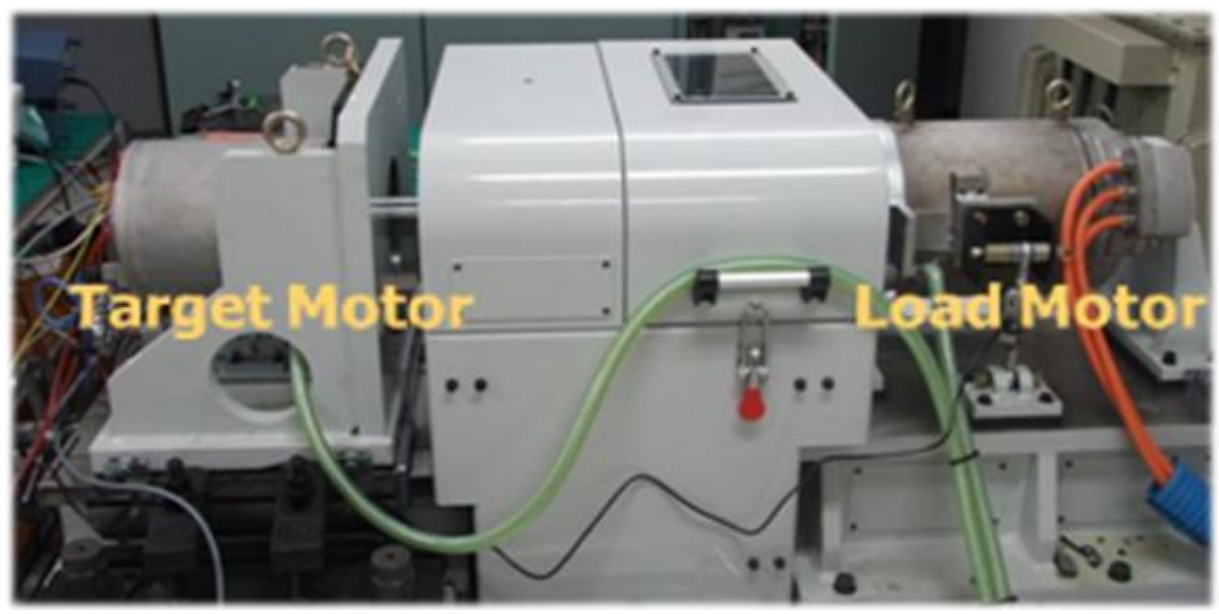

Figure 1. Experimental test structure and photo of test setup.

Two analog signals are crucial for the motor control, and are sent to the microprocessor. The current sensor signals are connected to the A/D port. They are converted into digital signals in the microprocessor. The resolver signals are converted into digital signals by R/D converter. The results are sent to the microprocessor.

To operate the EV motor described in table II, this inverter can output $40[\mathrm{~kW}]$ at continuous rating and $80[\mathrm{~kW}]$ at 30 seconds rating. As a power switching, an IGBT module is used, which can make a high speed switching, so as to comply with the demand for high power and high frequency specifications. The power module (Using a FS800R17KE3) provides six high power $(650 \mathrm{~V}, 800 \mathrm{~A})$. Furthermore, the power switching part and cooling part are laid out most suitably through the fin-pin type structure to downsize and to enhance cooling performance. Moreover, this inverter assembly is provided with protecting function against short-circuit, over current, over voltage, inverter overheat, etc.

TABLE I. Specification of the Motor

\begin{tabular}{|l|c|c|}
\hline \multicolumn{1}{|c|}{ Items } & specification & Unit \\
\hline Type & Interior permanent magnet motor & \\
\hline Poles & 4 & \\
\hline Rated output & 40 & $\mathrm{~kW}$ \\
\hline Maximum output & 80 & $\mathrm{~kW}$ \\
\hline Maximum torque & 220 & $\mathrm{Nm}$ \\
\hline Maximum speed (No load) & 10,000 & $\mathrm{rpm}$ \\
\hline Cooling method & Forced water cooling & \\
\hline
\end{tabular}

IABLE II. Specification of the Motor

\begin{tabular}{|l|c|c|}
\hline \multicolumn{1}{|c|}{ Items } & specification & Unit \\
\hline Control method & Torque control & \\
\hline Rated voltage & 360 & $\mathrm{~V}$ \\
\hline Rated output & 80 & $\mathrm{~kW}$ \\
\hline Maximum output frequency & 1 & $\mathrm{kHz}$ \\
\hline PWM frequency & $4 \sim 10$ & $\mathrm{kHz}$ \\
\hline Outside dimensions & $290 \times 260 \times 180$ & $\mathrm{~mm}$ \\
\hline Cooling method & Forced water cooling & \\
\hline
\end{tabular}

The high density of components in EV is very important. In order to achieve downsizing the inverter, the fin-pin structure mentioned above and integrated controller and cooling cover are applied. Figure 2 shows the inverter assembly. It is composed of power module, current sensors, power control unit, heat-sink, etc.

Figure 3 shows control block diagram of the IPM motor. For operating the IPM motor, basic torque control is applied. the mathematical model of an IPM motor in the d-q synchronously rotating reference frame for assumed sinusoidal stator excitation is applied [4]-[6]. 

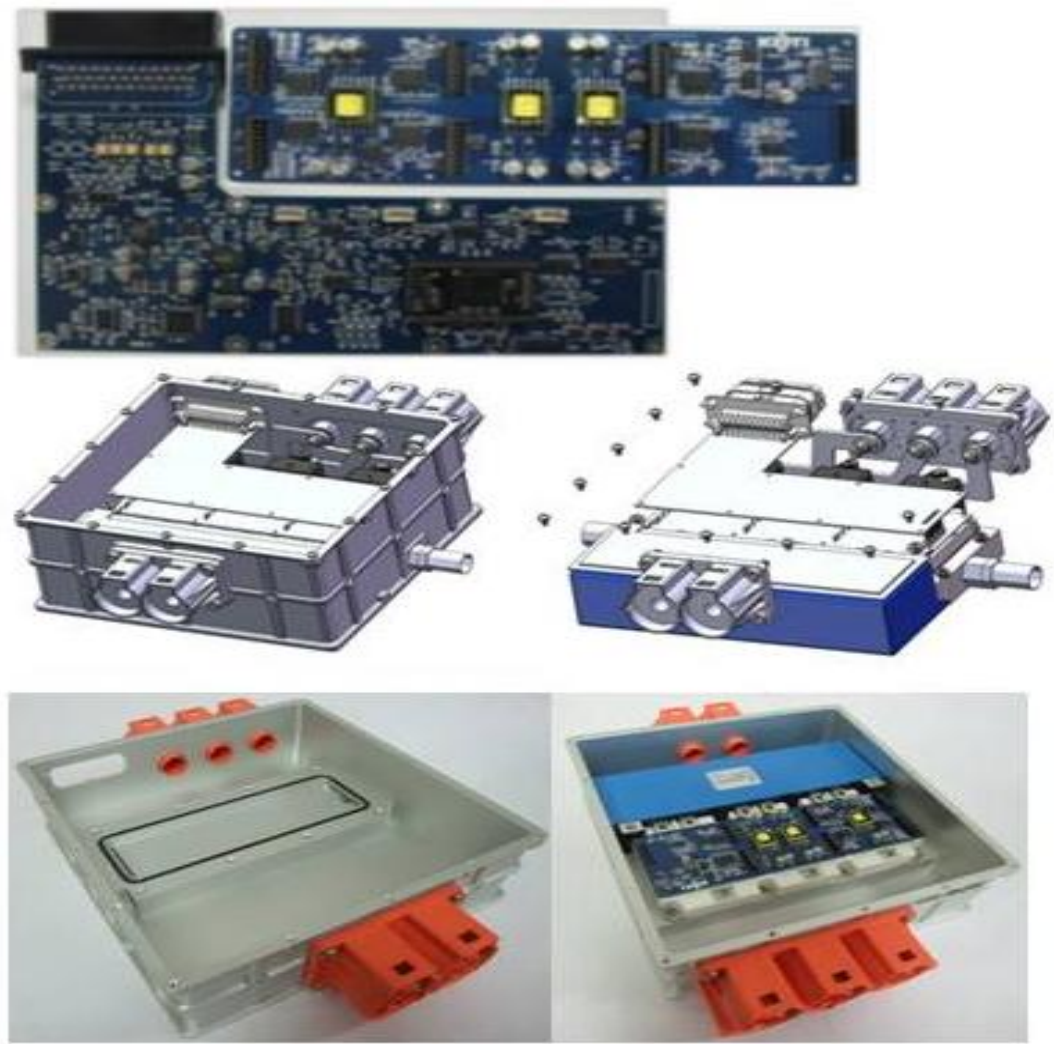

Figure 2. Inverter assembly.

For the evaluation for EV, we should determine the target entry and performance. The efficiency of the motor and inverter is first item. However the electric vehicle operates wide range of torque and speed. Therefore we should compare all range and main range of the efficiency. In addition, the basic specifications which are output power and torque should be compared.

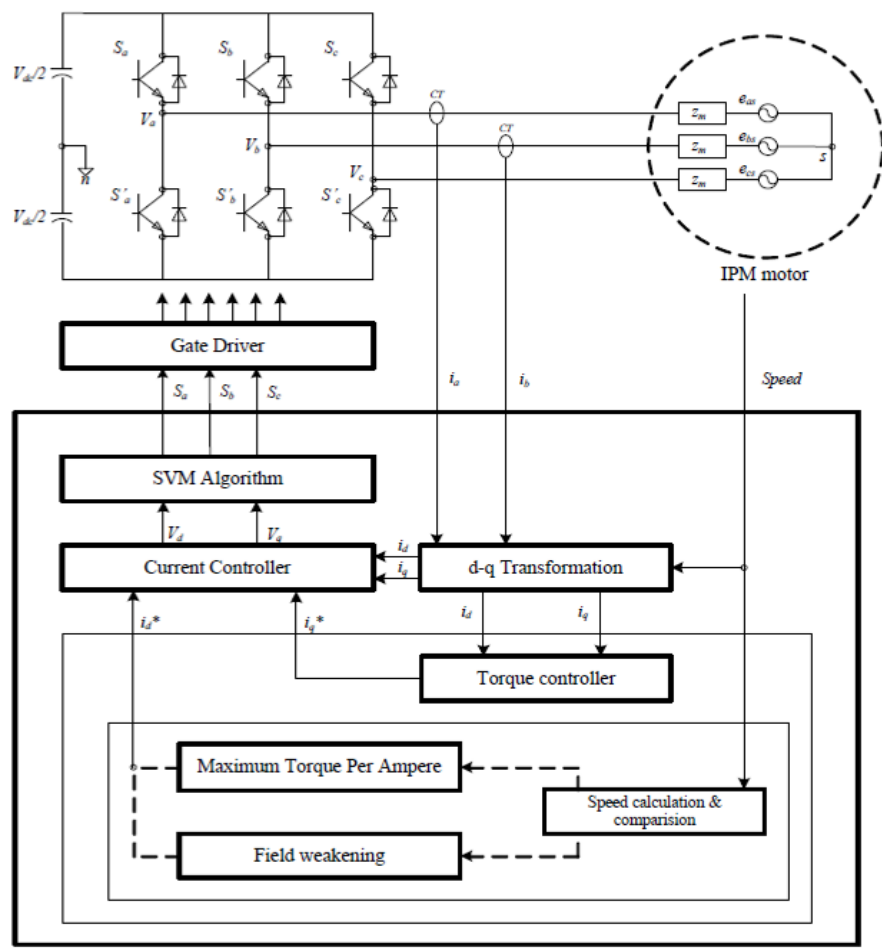

Figure 3. Control block diagram. 


\section{EXPERIMENTAL RESULTS}

Due to the strong magnetic field of the permanent magnet and the additional field generated by $i_{d}^{e}$ and

$i_{q}^{e}$, core is saturated and correspondingly $\mathrm{L}_{\mathrm{d}}$ and $\mathrm{L}_{\mathrm{q}}$ decrease. It is not straightforward to express the nonlinear saturation effects [6]. Therefore, it is better to rely on the look-up table in the mapping between torque and $\left(i_{d}^{e}, i_{q}^{e}\right)$.

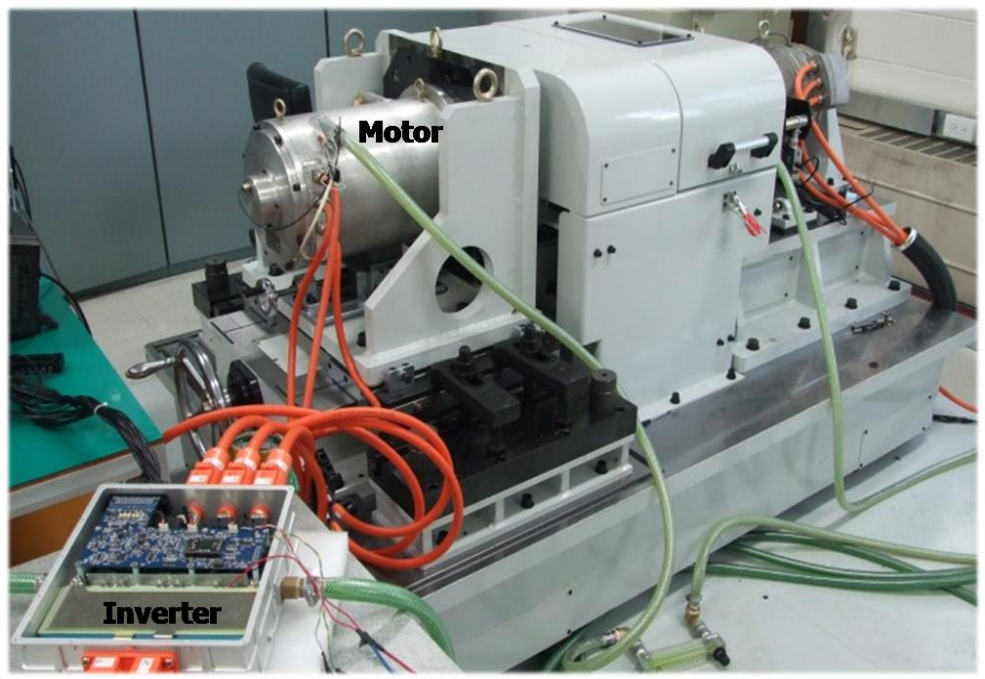

Figure 4. Experimental test setup.

In order to the mapping, experiment has been done with the dynamo system shown in Figure 4. The IPM motor is mechanically coupled to a dynamo motor via a torque transducer. Parameters of the IPM motor are shown in Table I. Motor was running in torque-control mode. In the test, the dynamo motor was running in speed-control mode, while the IPM motor was operating in torque-control mode. Figure 5 (a) shows the back-emf of IPM motor. The back-emf is sinusoidal and the phase difference is 120 electrical degrees apart. The waveforms of current and resolver output are shown in Figure 5 (b) The dynamo motor was running at $3550 \mathrm{rpm}$, and the torque command was $215 \mathrm{Nm}$.
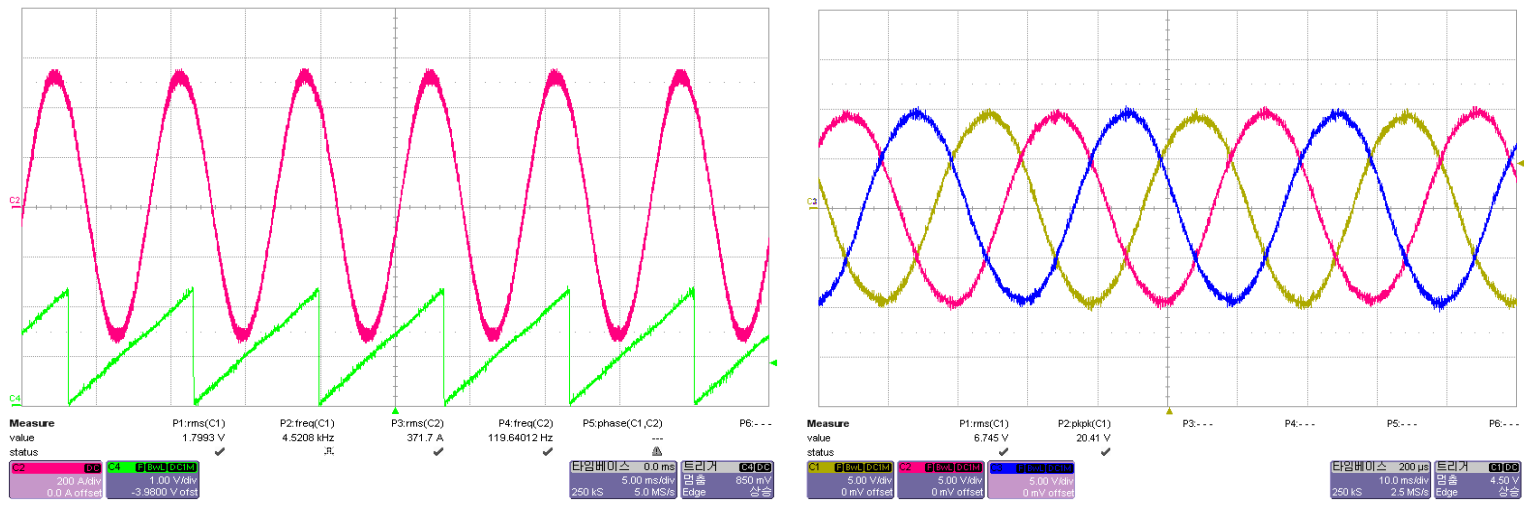

(a) Back-emf of the IPM motor.

(b) Waveforms of the motor current and the resolver output.

Figure 5. Waveforms of the IPM motor.

In the development of the inverter system, the temperature specification of some important elements should be tested. Figure 6 (a) shows the temperature of IGBT module and motor coil while the motor is operated at $220 \mathrm{Nm}$ which is maximum torque during 30 seconds. And Figure 6 (b) shows the temperature while the motor is repeatedly driven at $220 \mathrm{Nm}$ during 30 seconds.

The red line is phase current, the yellow line is speed which is 3,500rpm. The blue line is IGBT module and the green line is motor coil. The temperature of IGBT module is easily going back to ambient temperature. The cooling system is operated well and the elements of inverter system also operated well. 

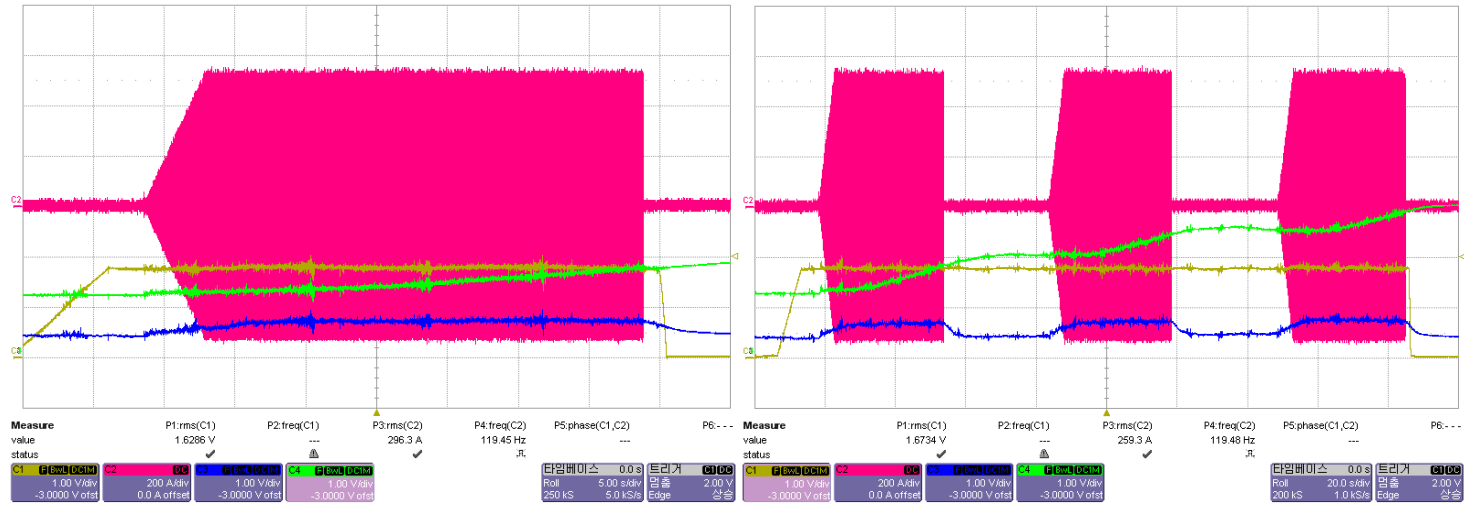

(a) Temperature at $215 \mathrm{Nm}$

(b) Temperature at $215 \mathrm{Nm}$ while operating repeatedly

Figure 6. Temperature while operating.

Figure 7 (a) shows the efficiency of the inverter. The maximum efficiency is 98.2 [\%].Figure 7 (b) shows the speed versus the phase current. The current was measured at fixed torque and variable speed. Figure 7 (c) shows the characteristic curves of the IPM motor. The constant torque and power control is operated well. The maximum efficiency is $97.5[\%]$ and the average efficiency of main region, which is from 40 to 80 [Nm] and from 2,000 to 6,000 [rpm], is 97 [\%].Figure 7 (d) shows the efficiency map of the IPM motor.

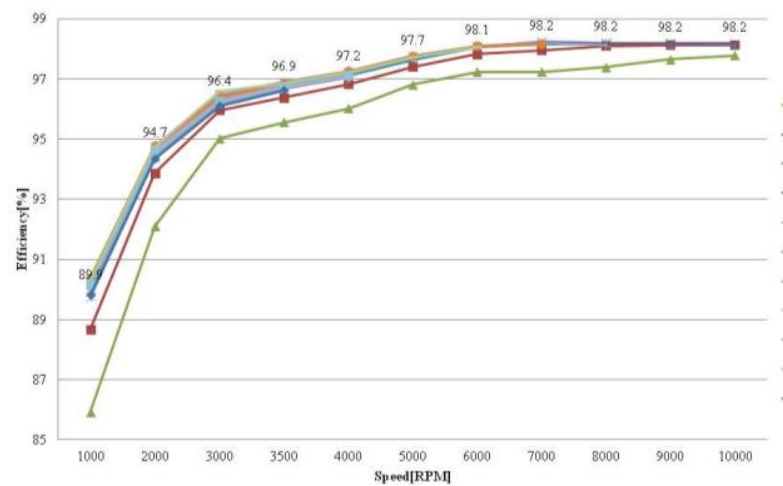

(a) Efficiency of the inverter.

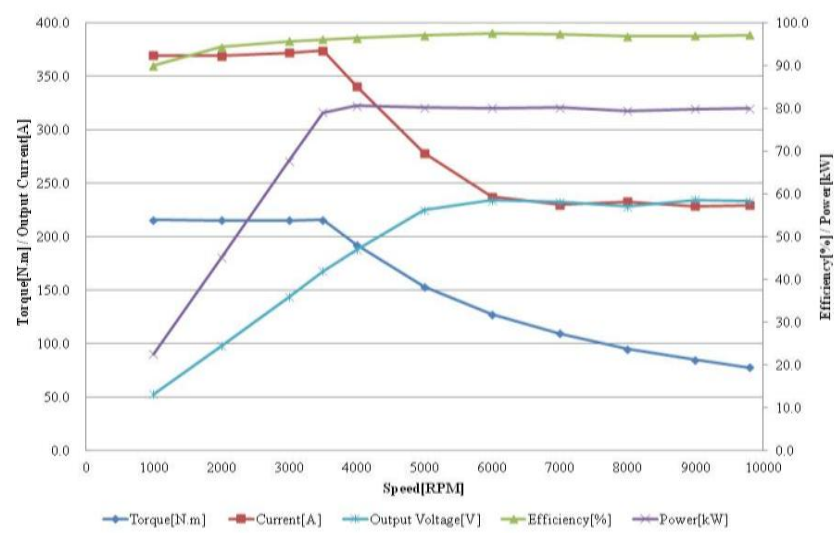

(c) Characteristic curves of the IPM motor.

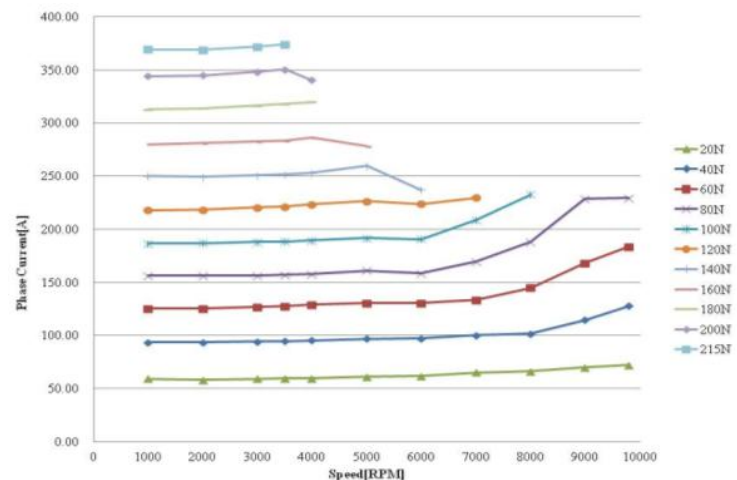

(b) Speed vs phase current.

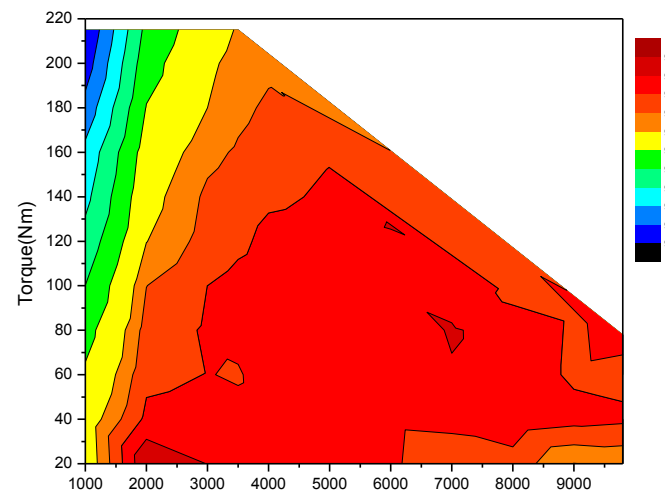

(d) Efficiency map of the IPM motor.

Figure 7. Test results of the IPM motor

\section{CONCLUSION}

This paper presents an experimental evaluation of IPM motor for EV. For the evaluation, the inverter system and cooling system are developed. In order to operate the inverter, basic algorithm of the IPM motor is applied. The evaluation has included both the constant torque and the power regions. The efficiency in all 
regions, which the motor can be operated, has been shown. From the experimental results, the IPM motor and inverter are operated well. The complete drive system has been successfully implemented for the IPM motor.

\section{REFERENCES}

[1] Araujo R. E., Ribeiro G., de Castro R.P., Oliveira H. S., Experimental Evaluation of a LossMinimization Control of Induction Motors used in EV, IECON, 2008, 1194-1199.

[2] Fu Z.X., Xiang J., Reynolds W.C., Nefcy B., Vector Control of An IPM Synchronous Machine Capable of Full Range Operations For Hybrid Electric Vehicle Application, IEEE $38^{\text {th }}$ IAS Annual meeting, vol. 3, 2003, 1443-1450.

[3] Umeda M., Itoh H., Hashimoto S., Hirata M., Tsujimura J. and Kato S., Permanent Magnet Motor for EV, IEEE Power Electronics and Drive Systems, vol. 2, 1995, 792-796,.

[4] T. S. Radwan, M. A. Rahman, A. M. Osheiba, and A. E. Lasine, Performance of a hybrid currentcontrolled VSI-fed permanent magnet synchronous motor drives, in Proc. IEEE PESC Conf. Rec., vol. 1, Italy, June 1996, 951-957.

[5] M. N. Uddin, T. S. Radwan, and M. A. Rahman, Performance of interior permanent magnet motor drive over wide speed range, IEEE Trans. on Energy Conversion, vol. 17, 2002, 79-84.

[6] Gubae Rang, Jaesang Lim, Kwanghee Nam, Hyung-Bin Ihm and HoGi Kim, A MTPA Control Scheme for an IPM Synchronous Motor Considering Magnet Flux Variation Caused by Temperature, APEC $19^{\text {th }}$ Annual IEEE, vol. 3, 2004, 1617-1621. 